\title{
Assessment of Genetic Diversity and Variety Identification Based on Developed Retrotransposon- Based Insertion Polymorphism (RBIP) Markers in Sweet Potato (Ipomoea Batatas (L.) Lam)
}

\section{Yusha Meng}

Zhejiang Academy of Agricultural Sciences

\section{Wenjin Su}

Hubei Academy of Agricultural Sciences

\section{Yanping Ma}

Zhejiang Academy of Agricultural Sciences

Lei Liu

Zhejiang Academy of Agricultural Sciences

\section{Xingguo Gu}

Zhejiang Academy of Agricultural Sciences

Dianxing Wu

Zhejiang University

\section{Xiaoli Shu}

Zhejiang University

\section{Qixian Lai}

Zhejiang Academy of Agricultural Sciences

\section{Yong Tang}

Zhejiang Academy of Agricultural Sciences

liehong Wu

Zhejiang Academy of Agricultural Sciences

\section{Yin Wang ( $\nabla$ wangyin@zaas.ac.cn )}

Zhejiang Academy of Agricultural Sciences

\section{Research Article}

Keywords: LTR retrotransposon, RBIP, molecular markers, genetic diversity, sweet potato

Posted Date: April 19th, 2021

DOI: https://doi.org/10.21203/rs.3.rs-414180/v1 
License: (c) (i) This work is licensed under a Creative Commons Attribution 4.0 International License. Read Full License 


\section{Abstract}

Sweet potato, a dicotyledonous and perennial plant, is the third most crucial tuber/root crop species behind potato and cassava in terms of production. Long terminal repeat (LTR) retrotransposons are highly abundant in sweet potato, contributing to genetic diversity. These LTR retrotransposons play a significant role in sweet potato genotypes. Retrotransposon-based insertion polymorphism (RBIP) is a high-throughput marker system to study the genetic diversity of plant species. To date, there have been no transposon marker-based genetic diversity analyses of sweet potato. We report a structure-based analysis of the sweet potato genome for the main LTR-retrotransposon subfamilies, Ty3-gypsy and Ty1copia, which revealed a total of 21555 LTR retrotransposons. By searching using hidden Markov models (HMMs), 1616 LTR retrotransposon sequences containing at least two models were found. A total of 48 RBIP primers were synthesized based on the high copy numbers of conserved LTR sequences. RBIP markers of the genetic diversity and population structure of 105 sweet potato germplasm resources revealed 56 amplicons with an average polymorphism of $91.07 \%$. Sweet potato accessions were collected from 6 provinces of China, Japan and America. A UPGMA dendrogram, a model-based genetic structure and principal component analysis (PCA) divided the sweet potato germplasms into 3 groups containing 8, 53, and 44 germplasms. All three analyses produced significant groupwise consensus. However, almost all the germplasms contained only one primary locus. The analysis of molecular variance (AMOVA) among the groups indicated higher intergroup genetic variation (53\%) than intrapopulation genetic variation. In addition, long-term self-retention may cause some germplasm resources to exhibit variable segregation. These results suggest that these sweet potato germplasms are not well evolutionarily diversified, although geographic speciation could have occurred at a limited level. This study highlights the utility of RBIP markers for determining the intraspecies variability of sweet potato.

\section{Introduction}

Sweet potato (Ipomoea batatas (L.) Lam.) is regarded as the world's seventh most important food crop and can be used as a staple food, animal feed, industrial raw material to extract starch as well as in alcohol and biofuel. In addition, orange-fleshed sweet potato has a high level of $\beta$-carotene, which could be used to prevent vitamin A deficiency-related blindness and maternal mortality in many developing countries. Due to its high productivity and adaptability to a wide range of environmental conditions, sweet potato is cultivated in more than 100 countries worldwide, particularly in the developing countries of Sub-Saharan Africa and South Asia. China is the largest producer of sweet potato, where several cultivars have been developed over 100 years of cultivation. However, information regarding the genetic diversity of Chinese sweet potato germplasm remains limited due to the complicated genome of this species, which limits the process of developing improved cultivars ${ }^{1,2}$. To establish effective breeding strategies, it is necessary to analyze the genetic diversity, evaluate the genetic structure and understand the genetic background among sweet potato accessions. 
In recent years, several morphological and molecular markers have been developed to assess the genetic diversity of sweet potato germplasm, including random amplified polymorphic DNAs (RAPDs) $3,4,5$, amplified fragment length polymorphisms (AFLPs) ${ }^{6,7}$ (Li et al., 2009; Liu et al., 2012), simple sequence repeats (SSRs) ${ }^{8,9,10}$, and single nucleotide polymorphisms (SNPs) ${ }^{2}$. However, for the massive genome sequences of sweet potato, these published markers are not sufficient to construct a high-density genetic map that could be highly useful for genetic studies. Thus, there is a great need for the exploration of new molecular markers.

Repetitive sequences make up a large proportion of the plant genome. Among repetitive sequences are transposable elements (TEs), which are grouped into two main classes according to their transposition intermediate ${ }^{11}$. Retrotransposons are a widespread class of TEs that exist in all plant species investigated to date ${ }^{11}$. Long terminal repeat (LTR) retrotransposons are one of the most important transposon families ${ }^{12,13}$. LTRs are easy to find because of their presence as flanking sequences at the $5^{\prime}$ and $3^{\prime}$ ends of coding regions in the genome ${ }^{14}$. Based on the above characteristics and their ubiquitous distribution, abundant copy number and insertion polymorphisms, LTRs are valuable for developing new molecular markers ${ }^{15,16}$. Compared with the traditional molecular markers mentioned above, retrotransposon-based markers have advantages including abundant polymorphisms and good reproducibility and genome coverage. Recently, several types of retrotransposon-based DNA markers have been developed and widely applied in evaluating genetic diversity and constructing linkage maps of numerous plant species $1,17,18,19,20,21,22,23,24$. These studies have confirmed that retrotransposon-based DNA markers are suitable for genetic diversity analysis. Unfortunately, there are few reports on the application of retrotransposon-based DNA markers in assessing the genetic diversity of sweet potato.

In this research, we report the development of new retrotransposon-based insertion polymorphism markers (RBIPs) derived from the genome sequence of the sweet potato cultivar Taizhong No. 6 (China national accession number 2013003) and evaluated the capacity and efficiency of these markers for distinguishing genetic diversity in 105 cultivars. The primary objective of this work is to provide new insights into the classification of sweet potato and to assist in the genetic research and breeding of sweet potato.

\section{Results}

\subsection{Discovery and classification of LTR retrotransposons in the sweet potato genome}

A total of 21555 LTR retrotransposons were obtained, making up $1.1 \%$ of the sweet potato genome $\mathrm{e}^{25}$ $(870 \mathrm{Mb})$. According to the sequence similarity with the reported retrotransposons, 13002 LTR retrotransposons were assigned to the copia family, 8114 LTR retrotransposons belonged to the gypsy family, and 439 LTR retrotransposons were classified to other families. The copia retrotransposons were further clustered into 12342 subfamilies with a single LTR retrotransposon sequence, 23 subfamilies with 
two LTR retrotransposon sequences, and 85 subfamilies with three or more LTR retrotransposon sequences (Table 1). The gypsy retrotransposons were clustered into 7775 subfamilies with a single LTR retrotransposon sequence, 37 subfamilies with two LTR retrotransposon sequences, and 49 subfamilies with three or more LTR retrotransposon sequences (Table 1). After searching HMM models in the 21555 LTR retrotransposons, 1616 LTR-RT sequences containing at least two models were screened and used for subsequent analysis. The 1616 LTR-RT sequences included 1311 copia families and 305 gypsy families.

Table 1

Classification of LTRs in different families and subfamilies

\begin{tabular}{|lllll|}
\hline $\begin{array}{l}\text { Subfamily cluster } \\
\text { number }\end{array}$ & \multicolumn{3}{l}{ Copia family } & Gypsy family \\
\cline { 2 - 5 } & $\begin{array}{l}\text { Subfamily } \\
\text { number }\end{array}$ & $\begin{array}{l}\text { LTR-RT } \\
\text { number }\end{array}$ & $\begin{array}{l}\text { Subfamily } \\
\text { number }\end{array}$ & $\begin{array}{l}\text { LTR-RT } \\
\text { number }\end{array}$ \\
\hline 1 & 12342 & 12342 & 7775 & 7775 \\
\hline 2 & 23 & 46 & 37 & 74 \\
\hline$>=3$ & 85 & 614 & 49 & 265 \\
\hline Total & 12450 & 13002 & 7861 & 8114 \\
\hline
\end{tabular}

\subsection{Development and evaluation of RBIP primers}

According to the principle of primer design, 48 pairs of RBIP primers were finally developed from the 1616 LTR-RT sequences, 6 pairs were from the copia 1 subfamily, 15 pairs were from the copia 2 subfamily, and 27 pairs were from the gypsy 2 subfamily (Supplementary Table 1). The Tm values of the RBIP primers ranged from $51.1^{\circ} \mathrm{C}$ to $59.12^{\circ} \mathrm{C}$, and the GC content ranged from $35-55 \%$. The length of the amplified products was $152 \sim 993 \mathrm{bp}$, with an average of $456 \mathrm{bp}$ (Supplementary Table 1).

The 48 RBIP primers were evaluated in 105 sweet potato germplasm resources (Table 2) and generated 64 marker candidates (23, no amplification; 6 , monomorphism; 13 , unstable amplification among resources) (Supplementary Fig. 1). The remaining 6 (12.5\%) pairs of primers (4 from the copia 2 subfamily, 2 from the gypsy 2 subfamily) showed clear and stable amplified fragments with polymorphisms among the 105 resources. 
Table 2

The 105 sweet potato germplasms used in this study and their origins

\begin{tabular}{|c|c|c|c|c|c|}
\hline Number & Name & Origin & Number & Name & Origin \\
\hline 1 & Jinqing & Xiaoshan District & 54 & Xiaoshanjinqing & $\begin{array}{l}\text { Xiaoshan } \\
\text { District }\end{array}$ \\
\hline 2 & Linhai & Linhai City & 55 & Hongpibaixin-6 & $\begin{array}{l}\text { Chun'an } \\
\text { County }\end{array}$ \\
\hline 3 & Huyuan & Jinyun County & 56 & Datoubai & $\begin{array}{l}\text { Cangnan } \\
\text { County }\end{array}$ \\
\hline 4 & Chaoshu & Cangnan County & 57 & Xinhong 3 & $\begin{array}{l}\text { Cangnan } \\
\text { County }\end{array}$ \\
\hline 5 & Zitong 1 & Chun'an County & 58 & Liusiguang & $\begin{array}{l}\text { Jinyun } \\
\text { County }\end{array}$ \\
\hline 6 & Zhe 81 & $\begin{array}{l}\text { Zhejiang Academy } \\
\text { of Agricultural } \\
\text { Sciences }\end{array}$ & 59 & Xiaoshanlouta & $\begin{array}{l}\text { Xiaoshan } \\
\text { District }\end{array}$ \\
\hline 7 & Liushiri-1 & Fuyang District & 60 & Lianhuaru & $\begin{array}{l}\text { Cangnan } \\
\text { County }\end{array}$ \\
\hline 8 & Hongpibaixin-1 & Wuyi County & 61 & Zhe 38 & $\begin{array}{l}\text { Zhejiang } \\
\text { Academy } \\
\text { of } \\
\text { Agricultural } \\
\text { Sciences }\end{array}$ \\
\hline 9 & Shenglibaihao-1 & Chengzhou City & 62 & Guangshu 87 & $\begin{array}{l}\text { Guangdong } \\
\text { Academy } \\
\text { of } \\
\text { Agricultural } \\
\text { Sciences }\end{array}$ \\
\hline 10 & Xushu $18-1$ & Chengzhou City & 63 & Zheshu 2 & $\begin{array}{l}\text { Zhejiang } \\
\text { Academy } \\
\text { of } \\
\text { Agricultural } \\
\text { Sciences }\end{array}$ \\
\hline 11 & Nanjingzhong & Yongkang City & 64 & Zheshu 77 & $\begin{array}{l}\text { Zhejiang } \\
\text { Academy } \\
\text { of } \\
\text { Agricultural } \\
\text { Sciences }\end{array}$ \\
\hline 12 & Chaosheng 5 & Chengzhou City & 65 & Zhe 255 & $\begin{array}{l}\text { Zhejiang } \\
\text { Academy } \\
\text { of } \\
\text { Agricultural } \\
\text { Sciences }\end{array}$ \\
\hline 13 & Jiande & Jiande City & 66 & Shenglibaihao-5 & $\begin{array}{l}\text { Tongxiang } \\
\text { City }\end{array}$ \\
\hline
\end{tabular}




\begin{tabular}{|c|c|c|c|c|c|}
\hline Number & Name & Origin & Number & Name & Origin \\
\hline 14 & Jizhuafanshu & Chun'an County & 67 & Hongpibaixin-7 & $\begin{array}{l}\text { Dongyang } \\
\text { City }\end{array}$ \\
\hline 15 & Anyangbaifanshu & Chun'an County & 68 & Zheshu 48 & $\begin{array}{l}\text { Zhejiang } \\
\text { Academy } \\
\text { of } \\
\text { Agricultural } \\
\text { Sciences }\end{array}$ \\
\hline 16 & Hangzhoufanshu & Pujiang County & 69 & Midong & $\begin{array}{l}\text { Cangnan } \\
\text { County }\end{array}$ \\
\hline 17 & Shenglibaihao-2 & Linhai City & 70 & Hongpibaixin-8 & Jiande City \\
\hline 18 & Xinzhonghua-1 & Suichang County & 71 & Mei 1 & America \\
\hline 19 & Hongpibaixin-2 & Ninghai County & 72 & Zheshu 6025 & $\begin{array}{l}\text { Zhejiang } \\
\text { Academy } \\
\text { of } \\
\text { Agricultural } \\
\text { Sciences }\end{array}$ \\
\hline 20 & Hongpihuangxin-1 & Dongyang City & 73 & Xinxiang & $\begin{array}{l}\text { Zhejiang } \\
\text { Academy } \\
\text { of } \\
\text { Agricultural } \\
\text { Sciences }\end{array}$ \\
\hline 21 & Jinguahuangfanshu & Yongkang City & 74 & Zhezishu 5 & $\begin{array}{l}\text { Zhejiang } \\
\text { Academy } \\
\text { of } \\
\text { Agricultural } \\
\text { Sciences }\end{array}$ \\
\hline 22 & Baishu & $\begin{array}{l}\text { Zhejiang Academy } \\
\text { of Agricultural } \\
\text { Sciences }\end{array}$ & 75 & Nanshu 88 & $\begin{array}{l}\text { Nanchong } \\
\text { Sichuan } \\
\text { Academy } \\
\text { of } \\
\text { Agricultural } \\
\text { Sciences }\end{array}$ \\
\hline 23 & Chun'anhongxin & Chun'an County & 76 & Zhe 259 & $\begin{array}{l}\text { Zhejiang } \\
\text { Academy } \\
\text { of } \\
\text { Agricultural } \\
\text { Sciences }\end{array}$ \\
\hline 24 & Zipibaixin & Jiande City & 77 & Zhezishu 4 & $\begin{array}{l}\text { Zhejiang } \\
\text { Academy } \\
\text { of } \\
\text { Agricultural } \\
\text { Sciences }\end{array}$ \\
\hline 25 & Hongpibaixin-3 & Chun'an County & 78 & Fanshu-1 & $\begin{array}{l}\text { Quzhou } \\
\text { City }\end{array}$ \\
\hline
\end{tabular}




\begin{tabular}{|c|c|c|c|c|c|}
\hline Number & Name & Origin & Number & Name & Origin \\
\hline 26 & Shenglibaihao-3 & Sanmen County & 79 & Hongpibaixin-9 & $\begin{array}{l}\text { Haiyan } \\
\text { County }\end{array}$ \\
\hline 27 & Nanguafanshu-1 & Chun'an County & 80 & Zheshu 26 & $\begin{array}{l}\text { Zhejiang } \\
\text { Academy } \\
\text { of } \\
\text { Agricultural } \\
\text { Sciences }\end{array}$ \\
\hline 28 & Taiwanfanshu & Cangnan County & 81 & Zhe 20 & $\begin{array}{l}\text { Zhejiang } \\
\text { Academy } \\
\text { of } \\
\text { Agricultural } \\
\text { Sciences }\end{array}$ \\
\hline 29 & Beijingzi & Wuyi County & 82 & Huabei 18 & $\begin{array}{l}\text { Cangnan } \\
\text { County }\end{array}$ \\
\hline 30 & Hongpibaixin-4 & Xinchang County & 83 & Yongtaishu & $\begin{array}{l}\text { Cangnan } \\
\text { County }\end{array}$ \\
\hline 31 & Hongxinganshu & Jiashan County & 84 & Nanguafanshu-2 & $\begin{array}{l}\text { Chun'an } \\
\text { County }\end{array}$ \\
\hline 32 & Liushiri-2 & Longquan City & 85 & Suxiang 4 & $\begin{array}{l}\text { Cangnan } \\
\text { County }\end{array}$ \\
\hline 33 & Guangsiwu & Sanmen County & 86 & Gao'erganshu & $\begin{array}{l}\text { Pan'an } \\
\text { County }\end{array}$ \\
\hline 34 & Baifanshu & Yongkang City & 87 & Xinzhonghua-2 & $\begin{array}{l}\text { Cangnan } \\
\text { County }\end{array}$ \\
\hline 35 & Zhe 75 & $\begin{array}{l}\text { Zhejiang Academy } \\
\text { of Agricultural } \\
\text { Sciences }\end{array}$ & 88 & $\begin{array}{l}\text { Hongpihuangxin- } \\
2\end{array}$ & $\begin{array}{l}\text { Ninghai } \\
\text { County }\end{array}$ \\
\hline 36 & Hongtou & Jinyun County & 89 & Pingguofanshu & $\begin{array}{l}\text { Songyang } \\
\text { County }\end{array}$ \\
\hline 37 & Qingtengfanshu & Yongkang City & 90 & Xueshu & $\begin{array}{l}\text { Zhejiang } \\
\text { Academy } \\
\text { of } \\
\text { Agricultural } \\
\text { Sciences }\end{array}$ \\
\hline 38 & Zipihuangxin & Jiande City & 91 & Wanjinshu & $\begin{array}{l}\text { Liandu } \\
\text { County } \\
\text { Lishui City }\end{array}$ \\
\hline 39 & Hongpibaixin-5 & Chun'an County & 92 & Ganshu & $\begin{array}{l}\text { Pan'an } \\
\text { County }\end{array}$ \\
\hline 40 & Jinguafanshu & $\begin{array}{l}\text { Liandu County } \\
\text { Lishui City }\end{array}$ & 93 & Fanshu-2 & Jiande City \\
\hline
\end{tabular}




\begin{tabular}{|c|c|c|c|c|c|}
\hline Number & Name & Origin & Number & Name & Origin \\
\hline 41 & Xiaoshanmudong & Xiaoshan District & 94 & 71438 & $\begin{array}{l}\text { Zhejiang } \\
\text { Academy } \\
\text { of } \\
\text { Agricultural } \\
\text { Sciences }\end{array}$ \\
\hline 42 & Shiniuhongmudan & $\begin{array}{l}\text { Liandu County } \\
\text { Lishui City }\end{array}$ & 95 & Hongpibaixin-10 & $\begin{array}{l}\text { Shengzhou } \\
\text { City }\end{array}$ \\
\hline 43 & Zitong 2 & Chun'an County & 96 & Wugecha & $\begin{array}{l}\text { Jinyun } \\
\text { County }\end{array}$ \\
\hline 44 & Shenglibaihao-4 & Chun'an County & 97 & Modong & $\begin{array}{l}\text { Yuhuan } \\
\text { County }\end{array}$ \\
\hline 45 & Hongmudan & Cangnan County & 98 & Xushu 18-2 & $\begin{array}{l}\text { Xuzhou } \\
\text { Sweet } \\
\text { Potato } \\
\text { Research } \\
\text { Center }\end{array}$ \\
\hline 46 & Yuguateng & Cangnan County & 99 & Hongpibaixin-11 & $\begin{array}{l}\text { Chun'an } \\
\text { County }\end{array}$ \\
\hline 47 & Rui'an & Xiaoshan District & 100 & Zhezishu 1 & $\begin{array}{l}\text { Zhejiang } \\
\text { Academy } \\
\text { of } \\
\text { Agricultural } \\
\text { Sciences }\end{array}$ \\
\hline 48 & Baimahongxin & Chun'an County & 101 & Zhe 13 & $\begin{array}{l}\text { Zhejiang } \\
\text { Academy } \\
\text { of } \\
\text { Agricultural } \\
\text { Sciences }\end{array}$ \\
\hline 49 & Xiaoyeqingteng & Jinyun County & 102 & Zhezishu 6 & $\begin{array}{l}\text { Zhejiang } \\
\text { Academy } \\
\text { of } \\
\text { Agricultural } \\
\text { Sciences }\end{array}$ \\
\hline 50 & Mudanshu & Cangnan County & 103 & Zhecaishu 726 & $\begin{array}{l}\text { Zhejiang } \\
\text { Academy } \\
\text { of } \\
\text { Agricultural } \\
\text { Sciences }\end{array}$ \\
\hline 51 & Liushiri-3 & Suichang County & 104 & Zhe 21 & $\begin{array}{l}\text { Zhejiang } \\
\text { Academy } \\
\text { of } \\
\text { Agricultural } \\
\text { Sciences }\end{array}$ \\
\hline
\end{tabular}




\begin{tabular}{|lllcll|}
\hline Number & Name & Origin & Number & Name & Origin \\
\hline 52 & Jinguahuang & Yongkang City & 105 & Taizhong 6 & $\begin{array}{l}\text { Qingdao } \\
\text { agricultural } \\
\text { Technology } \\
\text { Extension } \\
\text { Station }\end{array}$ \\
\hline 53 & Baixinfanshu & Jiashan County & & \\
\hline
\end{tabular}

\subsection{DNA fingerprinting and characteristics of RBIP markers}

In the 64 bands of the 6 pairs of RBIP primers, 51 polymorphic bands were used to generate a DNA fingerprint map of the 105 sweet potato cultivars. For each primer pair, the number of loci ranged from 7 to 14 with an average of 10.7, while the number of polymorphic bands varied from 6 to 11 with an average of 8.5 (Table 3). The polymorphic bands were converted to digital fingerprint data with presence as " 1 " and absence as " 0 ". A "1", "0" (Supplementary Table 2) digital fingerprint map was constructed by polymorphic loci. The digital fingerprint map was subsequently used to analyze the genetic diversity.

Table 3

Characteristics of the 6 RBIP primer pairs used for constructing sweet potato fingerprints

\begin{tabular}{|lllllll|}
\hline Name & No. of alleles & No. of polymorphic alleles & $\boldsymbol{N e}^{*}$ & $\boldsymbol{H}^{*}$ & $\boldsymbol{\mu}^{*}$ & PIC \\
\hline LTR10 & 7 & $6(85.71 \%)$ & 1.6464 & 0.3492 & 0.5111 & 0.2713 \\
\hline LTR11 & 10 & $9(90.00 \%)$ & 1.4024 & 0.2652 & 0.4237 & 0.2226 \\
\hline LTR13 & 12 & $9(75.00 \%)$ & 1.2206 & 0.1548 & 0.2761 & 0.1353 \\
\hline LTR20 & 9 & $6(75.00 \%)$ & 1.2534 & 0.1778 & 0.3064 & 0.1539 \\
\hline LTR37 & 12 & $10(83.33 \%)$ & 1.3808 & 0.2441 & 0.3931 & 0.2039 \\
LTR38 & 14 & $11(78.57 \%)$ & 1.1512 & 0.1253 & 0.2369 & 0.1149 \\
\hline Mean & 10.6666 & $8.5(79.69 \%)$ & 1.3231 & 0.2110 & 0.3479 & 0.1779 \\
\hline
\end{tabular}

POPGENE software ${ }^{26}$ was used to further dissect the genetic variation among the 105 sweet potato cultivars using the 6 pairs of RBIP primers. The effective number of alleles $\left(\mathrm{Ne}^{\star}\right)$ ranged from 1.1512 to 1.6464 , with an average of 1.3397 . Nei's gene diversity $\left(H^{\star}\right)$ ranged from 0.1253 to 0.3492 among various genomic groups. The maximum gene diversity was in LTR10, followed by LTR11. Shannon's index ( $\left.{ }^{*}\right)$ for each primer combination is also reported in Table 3. This index was highest in LTR10 (0.5111) but lowest in LTR38 (0.2369). To identify the most highly informative primer combination, the amount of polymorphism information content (PIC) was estimated from 0.1149 for LTR38 to 0.2713 for LTR10, with an average value of 0.1828 (Table 3 ).

\subsection{Genetic relationships among sweet potato accessions}

Bayesian modeling of the number of homogeneous gene pools $(K)$ in STRUCTURE ${ }^{27}$ was used to estimate the membership fractions of the 105 sweet potato accessions. An evaluation of the optimum 
value of $K$ following the procedure described by Evanno et al. ${ }^{28}$ indicated two clear optimal values for Delta $K$, at $K=2$ and 3 (Fig. 1), which indicated that a model with two gene pools captured a major split in the data and that substantial additional resolution was provided under a model with $K=3$. Barplots of the proportional allocations to each gene pool for $K=2$ and 3 were constructed in STRUCTURE and are shown in Fig. 2. The plots showed that these two models were related to each other hierarchically, such that the red cluster in the two-gene pool model was subdivided into two (blue and red) gene pools in the three-gene pool model.

The primary split in the data $(K=2)$ divided the accessions among two groups: group 1 and group 2 . Group 1 (red in Fig. 2) included 97 sweet potato accessions, one of which was from America, while the remainder were from different provinces in China, and the majority of all the samples were from Zhejiang Province. Group 2 (blue) comprised 8 samples, six of which were from Zhejiang Province, and the remaining 2 were from Jiangsu and Shandong Provinces. The accessions that demonstrated a low level of admixture, except "Xushu $18-1$ ", belonged to Ipomoea batatas (L.) Lam. The model with 3 gene pools was also supported by the STRUCTURE results. Under this model, group 1 in the $K=2$ model was further divided into two gene pools (red and blue), but the other gene pools remained almost the same (Fig. 2). The 3 groups included 53, 44, and 8 sweet potato accessions, respectively. In the $K=3$ model, group 1 and group 2 (red and blue) overlapped substantially with one another, and the hierarchical levels in these two clusters could hardly be recognized. All 97 accessions in group 1 and group 2 appeared to be from the two major gene pools. Several accessions from Jiangsu Province showed admixed origins, such as 'Xushu $18-1$ ', with three major gene pools.

A two-dimensional and three-dimensional PCA further depicted the relationship among the 105 sweet potato accessions (Fig. 3). In the two-dimensional PCA, Dim-1 and Dim-2 were 1.22 and 0.53 , respectively. The Dim-3 was 0.56 in the three-dimensional PCA. From the PCA diagrams, we could see that all the 105 sweet potato accessions were divided into two groups, group 1 and group 2 (green and red, 8 and 97, respectively), or three smaller groups, group 1, group 2, and group 3 (green, red, and blue, 8, 53, 44, respectively). The PCA results were similar to the STRUCTURE results at $K=2$, which classified all sweet potato accessions into two groups (red and blue, 97 and 8, respectively); however, in the $\mathrm{K}=3$ model, the red group was then divided into two groups (Fig. 2). The dimensionalities of the 3 groups indicated that the accessions in group 1 exhibited a higher genetic diversity than those in groups 2 and 3 .

Neighbor-joining cluster analysis clearly divided the 105 sweet potato accessions into 3 groups containing 8, 54, and 43 materials, respectively. This result was highly consistent with the assignments made using STRUCTURE. (Fig. 4). Group 2 was divided into 4 subgroups, containing 11, 14, 5, 13, and 11 materials. Group 3 was divided into 5 subgroups, containing 9, 6, 5, 4, and 19 materials. Group 1 included all improved varieties, except Hongpibaixin-11, which had large genetic distances from the other accessions. For several accessions, such as 'Jinguahuang' and 'nanguafanshu-2' as well as 'Hongpibaixin-2' and 'Hongpibaixin-3', the genetic distances between them were 0 , which meant that they had the same genotypes based on the 6 RBIP markers. The UPGMA dendrogram also showed that sweet potato accessions from the same regions were not well clustered in the same groups. For example, 22 
accessions from the Zhejiang Academy of Agricultural Sciences were scattered. It was obvious that these results coincided with the previous STRUCTURE and PCA results.

A population differentiation analysis was performed to analyze the genetic variations among and within groups, as revealed by the population structure. In the $K=3$ model, AMOVA revealed that $53 \%$ genetic differentiation $(P<0.001)$ of total molecular variance in the germplasm occurred among groups, and $47 \%$ $(P<0.001)$ was attributed to variation within groups (Fig. 5 , Table 4$)$. The total genetic variance among individuals within populations was significantly greater than $0(0.526)$, indicating that the genetic variation between and within the geographical population of the tested sweet potato resources was extremely significant (Table 4). Genetic distance among the 3 inferred groups revealed that Group 2 (blue) and Group 3 (green) had the highest differentiation with 0.819, and comparatively, Group 1 and Group 2 had a closer relationship with 0.265 . The pairwise fixation index $\left(F_{\mathrm{ST}}\right)$ values between the three populations were all 0.001 (Table 5).

Table 4

The AMOVA analysis results of 105 sweetpotato germplasms in the model of $K=3$

\begin{tabular}{|lclllllll|}
\hline Source & df & $\begin{array}{c}\text { Sum of } \\
\text { squares }\end{array}$ & $\begin{array}{l}\text { Mean of } \\
\text { squares }\end{array}$ & $\begin{array}{l}\text { Estimated } \\
\text { Variance }\end{array}$ & $\begin{array}{l}\text { Percentage of } \\
\text { total Variance }\end{array}$ & $\begin{array}{l}\text { AMOVA } \\
\text { statistics }\end{array}$ & Value & P \\
\hline $\begin{array}{l}\text { Among } \\
\text { Groups }\end{array}$ & 2 & 225.601 & 112.800 & 3.698 & $53 \%$ & & & \\
\hline $\begin{array}{l}\text { Within } \\
\text { Groups }\end{array}$ & 102 & 339.371 & 3.327 & 3.327 & $47 \%$ & PhiPT $^{4}$ & 0.526 & 0.001 \\
\hline Total & 104 & 564.971 & & 7.026 & $100 \%$ & & & \\
\hline
\end{tabular}

Table 5. Genetic distance (down diagonal) and pair fixation index ( $F_{\mathrm{ST}}$, up diagonal)

between three groups inferred by structure analysis

\begin{tabular}{|llll|}
\hline Group & Group_1 & Group_2 & Group_3 \\
\hline Group_1 & & 0.001 & 0.001 \\
Group_2 & 0.265 & & 0.001 \\
Group_3 & 0.727 & 0.819 & \\
\hline
\end{tabular}

\section{Discussion}

To support sweet potato breeding programs, it is essential to assess the genetic diversity and relationships among cultivars. The ubiquity and abundance of LTR retrotransposons in the plant genome have made them valuable for studying genome-wide variation and diversity. The retrotransposon-based genetic DNA fingerprinting method could provide potentially useful genetic information. The increasing amount of sequence data released by next-generation sequencing technology provides a valuable 
resource for the development of retrotransposon-based markers. These retrotransposon-based markers have been applied successfully to analyze the genetic diversity in various plant species.

In the current study, we confirmed that the LTRs of sweet potato accessions contained the full complement of LTR retrotransposons. Structural analysis revealed that they are transcriptionally active and could be functional. The developed RBIP primers produced both polymorphic and monomorphic alleles that enabled the use of RBIP DNA fingerprinting to evaluate the genetic diversity among the 105 sweet potato accessions. Based on this genome-wide analysis, we found that only $12.5 \%$ of RBIP markers generated polymorphic bands, signifying that inter-LTR regions in the research genome of sweet potato accessions were significantly conserved. This implies that the sweet potato genome is still under evolution and that LTRs are not very active in contributing to genome-wide variations. To the best of our knowledge, this is the first study of genetic diversity in sweet potato using RBIP-based fingerprinting.

A previous report indicated that $7.37 \%$ of the sweet potato genome (approximately $4.4 \mathrm{~Gb}$ ) was identified as an LTR (Si et al., 2016), while $10.987 \%$ of the sweet potato genome (approximately $4.4 \mathrm{~Gb}$ ) was identified as a full-length LTR retrotransposon in the present study. This small difference in the number of LTRs $(10.987 \%$ vs.) might be attributed to the different approaches and parameters that were used in the two studies. In our study, only putative full-length LTR retrotransposons with two very similar LTR sequences were isolated. The ratio of Ty3-gypsy to Ty1-copia can reflect the contribution in the sweet potato genome. Our results showed that full-length copia LTR retrotransposons were more common than gypsy retrotransposons in the sweet potato genome (Table 1). The ratio of Ty3-gypsy to Ty1-copia was (1:1.6), higher than that in a previous study $(1: 1.15)^{29}$. The numbers of full-length LTR retrotransposons in the different subfamilies were generally low, gypsy subfamilies had more single sequences $(95.8 \%)$ than copia subfamilies (94.9\%), and only $0.6 \%$ (49) contained more than 3 LTR retrotransposons. These findings are consistent with the results reported in other plants with different genome sizes ${ }^{30,31,32}$.

New bioinformatics software offers exciting perspectives for the development of new markers based on whole genome sequences. In the sweet potato genome, the most abundant retrotransposon families were copia and gypsy, accounting for $3.64 \%$ and $3.62 \%$, respectively. However, simple sequence repeats contribute only $1.94 \%$ of the genome ${ }^{29}$, which indicated that RBIP markers were more ubiquitous than SSR markers in sweet potato. Although many SSR markers have been developed from sweet potato, almost all SSRs (86.1\%) have mononucleotide or dinucleotide repeat motifs, and "stutter bands" or increased mutation rates in repeat lengths may create issues for using SSR markers ${ }^{33,34,35}$. RBIP markers amplify a single locus in samples, differing from SSR markers that potentially amplify two or possibly more homologous loci. Compared with other retrotransposon-based markers (IRAP, REMAP, and SSAP), which display polymorphisms in band size owing to retrotransposon insertion, RBIP markers can detect the presence or absence of retrotransposons in a locus produced by the integration of an element ${ }^{36}$.

In our 48 developed RBIP markers, 21 and 27 pairs of primers were related to the insertion of copia and gypsy retrotransposons in a particular locus, respectively. Due to the high similarity of LTRs from the same subfamily, primers designed with these LTRs may produce a same left primer sequences; for 
example, the left primer sequences of LTR10, LTR11, LTR13 and LTR20 were the same, but the downstream sequences were different, and this does not have an effect on the specific amplification. Diversity analysis showed that copia and gypsy LTR retrotransposons existed in all sweet potato varieties, which suggested that copia and gypsy retrotransposons existed in the sweet potato species for a long time. In several varieties, several primers did not amplify fragments, such as LTR10 in Zipibaixin, suggesting that these retrotransposons were not found in these loci. However, the insertion of copia and gypsy retrotransposons was extensively detected in most of the cultivars with more than one locus. These results implied that copia and gypsy retrotransposons replicated many times in the development of cultivated sweet potato and might explain why $10.98 \%$ of the genome was LTR retrotransposon in this research.

Additionally, previous RBIP markers of sweet potato were developed based on primer binding site construction libraries according to sequencing platforms and then LTR sequence screening. The markers generated by this method have strong specificity, and their polymorphism will be limited in other germplasm resources, so their application may be lower than that of genomic markers in genetic diversity analysis of this species. This study was based on the genome sequence of the sweet potato cultivar 'Taizhong 6 ' and included searching and screening LTR sequences. The RBIP markers we developed should have universal applicability in sweet potato resources.

According to the STRUCTURE analysis, the 105 germplasms can be divided into two groups when $K=2$ in STRUCTURE (Fig. 2). The STRUCTURE results indicated that the genetic background of the 105 sweet potato germplasms had two gene pools. Almost all the germplasms had unique backgrounds, except 'Xushu18-1', 'Jinguafanshu', and 'Taizhong6'. 'Xushu 18-1' (p330683034) was released by the Xuzhou Regional Agricultural Research Institute in 1972. It was selected from the cross between 'Xindazi' X '52 45 ' with an inbreeding backcross, and ' $52-45$ ' was a hybrid offspring of 'Nancy Hall' X 'Okinawa 100'. Previous studies have shown that most of the sweet potato cultivars have a genetic background of Okinawa 100 from Japan and Nancy Hall from the USA $37,38,7,10$. Based on the above research, we inferred that the two gene pools may be Nancy Hall and Okinawa 100. However, in the $K=3$ model in STRUCTURE (Fig. 2), most of the accessions had one major gene pool source and a small minor gene pool, except 'Xushu $18-1$ ', which had 2 main gene pools and a small minor gene pool. From these results, we can see that 'Xushu 18-1' has a wider genetic background than other accessions. The genetic background of sweet potato was single in Zhejiang, even among China, so it is necessary to broaden the genetic background of sweet potato varieties, enrich their genetic diversity and protect high-quality germplasm resources.

All the accessions can be divided into three groups (group I represented by green, group II by red, and group III by blue) according to the PCA results and UPGMA dendrogram (Fig. 3, Fig. 4). In group I, 7 of the 8 accessions were improved varieties, and the other 21 improved varieties were scattered in subgroups II and III. This result indicated that the genetic background of improved varieties had more similarity than other germplasms to some degree. 'Hongpibaixin- 11 ' is a variety selected by local farmers and known for its phenotypic traits such as leaf shape, root tuber skin color, and root tuber flesh color. There were 11 and 
9 improved varieties in groups II and III, respectively, and other landraces were scattered in the two groups. The varieties 'Zhe 38', '71438', 'Zhe 81', 'Zhe75', and 'Zheshu 48', which were improved by the Institute of Crop and Nuclear Technology Utilization, Zhejiang Academy of Agricultural Sciences, clustered on the third subgroup of group I, illustrating that these varieties had similar genetic backgrounds in the hybrid combination. 'Zhe 255' and 'Xinxiang', 'Zhezishu 5', 'Zheshu 6025' and 'Nanshu 88 ' were the same.

The results of the Bayesian model using $K=2$, the UPGMA dendrogram, and the PCA were highly consistent; group I contained 8 accessions, and group II consisted of 97 accessions. When $K=3$, the UPGMA dendrogram and PCA results were still consistent. Group I had 8 accessions ('Zhe 21', 'Zhecaishu 726', 'Hongpibaixin-14', 'Zhezishu 1', 'Xushu 18 - 2', 'Zhezishu 6', 'Zhe 13', 'Taizhong 6'), and 54 and 43 accessions were clustered in groups II and III, respectively. From the two-dimensional and threedimensional PCAs, we found that the sweet potato germplasms in the three groups were very concentrated, and the genetic differences of the three groups were obvious. The genetic distance between Group_1 and Group_2 was 0.265 , that between Group_1 and Group_3 was 0.727 , and that between Group_2 and Group_3 was 0.819 (Table 5). The above data indicated that Group_2 and Group_3 had the largest genetic information, followed by Group_1 and Group_3, and Group_1 and Group_2 had the smallest differences. The pairwise fixation index $\left(F_{\mathrm{ST}}\right)$, as a population differentiation index determined by genetic structure, can often be used to assess genome-wide variation. The mean FST value between the three groups were 0.001 , indicating that there was a very high level of differentiation between the three groups. The genetic diversity between the three groups was very large, and the germplasms in the three groups could be combined as a hybrid parent.

AMOVA showed that the source of variation among and within populations was $53 \%$ and $47 \%$, respectively, indicating that the genetic variance was significant in Zhejiang sweet potato germplasm resources (Fig. 5, Table 4). Most of the sweet potato resources in this study have been produced in Zhejiang Province for a long time, and local environmental conditions have a significant effect on genetic variation. This result was inconsistent with those of previous studies ${ }^{7,9}$. The proportion of the total genetic variance among individuals within populations (PhiPT) value was 0.526 , and $P<=0.001$, showing that the total genetic variance among individuals within populations was extremely significant.

We found that several germplasms with similar phenotypes were separated into close subgroups. For example, some germplasms, 'Hongpibaixin-7', 'Shenglibaihao-1', 'Fanshu-2', 'Shenglibaihao-4', 'shenglibaihao-2', 'shenglibaihao-3', and 'Hongpibaixin-8', with similar phenotypic characters of leaf shape, leaf teeth type, leaf color, stem primary color, root tuber skin color, and root tuber flesh color, clustered together in the second subgroup of the second group; The germplasms 'Hongpibaixin-4', 'Hongpibaixin-2', 'Hongpibaixin-3', 'Hongpibaixin-10', 'An'yangbaifanshu', 'Liushiri-1', 'Liushiri-2', 'Hongpibaixin-5' and 'Hongpibaixin-11', with similar phenotypic characters of leaf shape, leaf color, leaf teeth type, leaf vein color, leaf stalk color, stem primary color, root tuber skin color, root tuber flesh color, and root tuber shape, clustered in the fifth subgroup of the second group, while 'Hongpibaixin-11' and 'Hongpibaixin-4'; 'Jinguahuang', 'Nanguafanshu-2', 'Baimahongxin', 'Nanguafanshu-1', 'Chun'anhongxin', 
and 'Jinguahuangfanshu' were similar in leaf vein color, stem primary color, root tuber skin color, root tuber flesh color, and root tuber shape, and five of the germplasms were clustered together in the fourth subgroup of the second group. This phenomenon may be attributed to most of the germplasms collected from locals being used for planting for many years. Long-term self-retention may cause a germplasm resource to exhibit segregation of variables. The UPGMA genetic relationship reflects the difference in genetic background between germplasm resources, so selection of genetically distant accessions as hybrid parents in breeding is more likely to generate elite varieties. Our results have demonstrated the high potential of molecular marker-based parental selection in promoting genetic improvement in future sweet potato breeding programs.

However, several germplasm resources, such as 'Shenglibaihao-1', 'Shenglibaihao-2', 'Shenglibaihao-3', and 'Shenglibaihao-4', collected from different counties and cities of Zhejiang Province, called the same name (Shenglibaihao) by local people, were not similar in terms of the phenotypic characters of leaf vein color and leaf stalk color. Therefore, several germplasm resources were numbered and considered synonymous. From the results of the UPGMA dendrogram, however, we could see that those synonymous germplasm resources were not clustered together. They were not a same variety. 'Shenglibaihao', also named Okinawa 100, was bred in Japan and then introduced to China before the 1970 s. Almost $90 \%$ of the genetic background of improved varieties in the 1960s was filial generations of 'Shenglibaihao'37,38,7,10. The filial generations that have phenotypic traits similar to those of 'Shenglibaihao' may also be called 'Shenglibaihao' by farmer breeders, which could be the reason why there were resources named 'Shenglibaihao-1', 'Shenglibaihao-2', 'Shenglibaihao-3', and 'Shenglibaihao-4', with different variations but clustered together. The synonymous landraces 'Hongpibaixin', 'Liushiri', and 'Fanshu' have similar situations. The landraces 'Hongpibaixin-2' and 'Hongpibaixin-3', collected from Cangnan County, Wenzhou City, and Jinyun County, Lishui City, Zhejiang Province, China, respectively, showed $100 \%$ similarity in the UPGMA dendrogram, STRUCTURE, and PCA results. The 6 RBIP primer pairs used in this study amplified the same fragments in these two accessions (Supplementary Table 2), so we speculated that these two accessions might be synonyms. To confirm this speculation, we investigated their phenotypic traits, including leaf shape, leaf tooth type, top bud color, tip hair color, leaf vein color, petiole color, stem primary color, stem secondary color, root tuber shape, root tuber skin color, and root tuber flesh color (Supplementary Table 3), and found that they indeed have the same phenotypic characters. The same situations existed between 'Jinguahuang' and 'Nanguafanshu-2' as well as 'Zheshu 77' and 'Lianhuaru'. This result revealed that 'Jinguahuang' and 'Nanguafanshu-2'/'Zheshu 77' and 'Lianhuaru' were the same germplasms. However, we did not observe the same phenotypic characteristics between 'Hongmudan' and 'Hongtou', 'Chaosheng 5' and 'Jinqing', 'Zhe 259' and 'Shiniuhongmudan'. The reason may be that these sweet potato germplasm resources had very similar genetic backgrounds, and more markers will be needed to confirm their relationships.

\section{Conclusions}


In this study, we successfully developed 48 RBIP primer pairs from the sweet potato genome, and successfully analyzed the genetic diversity and constructed a fingerprint of 105 sweet potato germplasm resources based on 6 RBIP primer pairs. These sweet potato germplasm resources exhibited a high level of genetic similarity, indicating the utility of RBIP markers for variety identification in sweet potato. These highly polymorphic RBIP primer pairs have the potential to be used as core primer pairs for variety identification, genetic diversity assessment and linkage map construction in sweet potato. The UPGMA dendrogram could provide a good theoretical reference and guidance for germplasm research and breeding.

\section{Materials And Methods}

\subsection{Plant materials and DNA extraction}

All 105 sweet potato cultivars used in the present study are donated by the Sweet potato Germplasm Repository, the Institute of Crop and Nuclear Technology Utilization, Zhejiang Academy of Agricultural Sciences, Hangzhou, China (Table 2). They collected these resources from Zhejiang Province according to the < Implementation Plan of the Third National Crop Germplasm Resources Survey and Collection Action > issued by the Ministry of Agriculture and Rural Affairs of China.The samples included 26 improved varieties, 78 landraces from different geographical regions and 1 introduced variety from the United States of America. Total genomic DNA was extracted from fresh young leaves with the modified cetyltrimethylammonium bromide (CTAB) method described by Saghai-Maroof et al. ${ }^{39}$ The quality and quantity of DNA were detected using spectrophotometric analyses and 1\% (w/v) agarose gel electrophoresis, respectively. The DNA was diluted to a final concentration of $50 \mathrm{ng} / \mu \mathrm{L}$ and then stored at $-80^{\circ} \mathrm{C}$ for further use.

\subsection{LTR-RT prediction in the sweet potato genome}

The full-length sequences of LTRs were predicted using LTR harvest software based on the genomic data of sweet potato variety 'Taizhong 6', which was downloaded from the website http://public-genomesngs.molgen.mpg.de/Sweet potato/. The parameters of LTR harvest were set as follows: (1) the length range of the LTRs was $100 \sim 1000 \mathrm{bp}$; (2) the distance between the starting points of the LTRs was $1000-15000 \mathrm{bp}$; (3) the similarity threshold was $85 \%$; (4) the repeat sequence length of each target site was $4 \sim 20 \mathrm{bp}$; (5) there were $4 \sim 6 \mathrm{bp}$ target site duplications (TSDs) or polypurine tracts (PPTs) and primer binding sites (PBSs) on both sides of two identical LTRs; and (6) the other software parameters were set to the default options. The sequences of predicted LTRs were translated into six codes to obtain the corresponding protein sequences. All the copia and gypsy gene models were downloaded from the PFAM tadabase (gag, pf03732; integrate, pf00665; reverse transcriptase, pf00078 and pf07727) (http://pfam.xfam.org/), and an HMM model (gag, INT, RT) was constructed based on the downloaded data. The functional domain sequences of LTR protein sequences were subsequently analyzed using BLASTN searches (E-value < 1e-10) against the HMM models. By searching the three models in each 
protein sequence, LTRs containing at least two models were screened for subsequent analysis. The screening criteria were a full-length E-value $<1 \mathrm{e}-10$ and an optimal domain E-value $<1 \mathrm{e}-10$.

\subsection{Development and evaluation of RBIP primers}

The RBIP primers were designed by Primer $3^{40}$. One primer was designed from LTR sequence and another was designed from flanking genome sequence. The design principles were as follows: (1) the primer length was 18-25 bp; (2) the amplified products were 100-1000 bp; (3) the GC content of the primers was $35 \% \sim 55 \%$; (4) the annealing temperature was $50 \sim 60^{\circ} \mathrm{C}$; and (5) the annealing temperature difference between upstream and downstream primers was less than $5^{\circ} \mathrm{C}$. The designed primers were synthesized by Beijing Tsingke Biotechnology Co., Ltd.

PCR amplification was carried out in $15 \mu \mathrm{L}$ reaction solution consisting of $1 \mu \mathrm{L}$ DNA template, $7.5 \mu \mathrm{L}$ Tsingke Master Mix (Tsingke, Beijing, China), $1 \mu \mathrm{L}$ (10 $\mu \mathrm{mol} \mathrm{L}-1)$ each RBIP primer (Tsingke, Beijing, China) and $4.5 \mu \mathrm{L}$ deionized distilled water. PCR amplification was performed with the following procedure: $94^{\circ} \mathrm{C}$ for $5 \mathrm{~min}$ followed by 35 cycles at $94^{\circ} \mathrm{C}$ for $30 \mathrm{~s}, 58 \sim 60^{\circ} \mathrm{C}$ (depending on the RBIP primers) for $30 \mathrm{~s}, 72^{\circ} \mathrm{C}$ for $30 \mathrm{~s}$, a final extension at $72^{\circ} \mathrm{C}$ for $5 \mathrm{~min}$, and storage at $4^{\circ} \mathrm{C}$. Amplicons were analyzed by electrophoresis on a $2 \%(\mathrm{w} / \mathrm{v})$ agarose gel. Amplicons were pooled together with an internal size standard (ABI GeneScanTM 500 LIZ, Applied Biosystems, Foster City, USA) and loaded on an ABI Genetic Analyzer (3730XL, Applied Biosystems, Foster City, USA). Accurate allele points were analyzed by Gene mapper 4.1 software ${ }^{41}$.

\subsection{Data analysis}

Characteristics of the RBIP primer pairs developed for analyzing sweet potato genetic diversity were evaluated in the 105 sweet potato accessions in terms of the effective number of alleles $\left(\mathrm{Ne}^{\star}\right)$, Nei's gene diversity $\left(H^{\star}\right)$, Shannon's information index $\left({ }^{*}\right)$ and polymorphism information content (PIC) using POPGENE version $1.32^{26}$ and the Botstein formula ${ }^{42}$, respectively.

For nonhierarchical genotypic clustering, the number of homogeneous gene pools $(K)$ was modeled using the genotypes obtained from all 105 individuals in the software STRUCTURE version 2.3.3, which uses the Markov chain Monte Carlo (MCMC) algorithm ${ }^{43,44}$. This revealed the genetic structure by assigning individuals or predefined groups to $K$ clusters. Twenty runs of STRUCTURE were performed by setting the number of clusters $(K)$ from 2 to 10 . Each run consisted of a burn-in period of 100,000 iterations followed by 100,000 MCMC iterations, assuming an admixture model. The results were uploaded to the STRUCTURE HARVESTER website (http://taylor0.biology.ucla.edu/STRuctureHarvester/27) to estimate the most appropriate $K$ values. The replicate cluster analysis of the same data resulted in several distinct outcomes for estimated assignment coefficients, even though the same starting conditions were used. Therefore, CLUMPP software was employed to average the 20 independent simulations, and the results were illustrated graphically using DISTRUCT ${ }^{45}$. 
All the " 1 " and " 0 " data were used to calculate Dice's similarity coefficients and genetic distances 46 among the 105 sweet potato accessions by the NTSYS-pc version 2.2 statistical package ${ }^{47}$. A UPGMA dendrogram based on the genetic distance matrix was constructed by MEGA X software ${ }^{48}$ to evaluate genetic relationships among the sweet potato varieties. Two-dimensional and three-dimensional PCAs were constructed with the $\mathrm{R}$ statistical package $\mathrm{e}^{49}$ and used to indicate the distribution of individual varieties in the scatter diagram.

To investigate the genetic differentiation among the 105 sweet potato accessions, AMOVA was performed based on population inference according to structure analysis by the software Arlequin v3. $5^{50}$, with 1,000 permutations and sum of square size differences as molecular distance. Furthermore, pairwise differentiation levels were estimated by the pairwise $F_{\mathrm{ST}}$, a measure of heterozygosity among populations relative to heterozygosity within populations ${ }^{51}$.

\section{Declarations}

\section{Acknowledgements}

This research was funded by the Project of Creative Agriculture Derived R\&D and Demonstrations of Horticultural Varieties (2018C02057) and the Research and Demonstration project of the Key Technology of Agricultural Cultivation Systems in Urban Building Terrace (20180416A07).

\section{Author Contributions}

Yusha Meng and Wenjin Su designed the research. Yanping Ma, Lei Liu, and Xingguo Gu planted and harvested experimental accessions. Liehong Wu performed phenotype evaluations. Yusha Meng analyzed data and wrote the paper. Yin Wang, Dianxing Wu, and Xiaoli Shu revised the paper. Qixian Lai and Yong Tang funded the research. All authors have read and agreed to the published version of the manuscript.

\section{Additional information}

Supplementary Materials Supplementary: Figure 1 locus information on 2 sweet potato accessions amplified by LTR-13 primer pair, Table S1: RBIP primers designed from the copia and gypsy subfamily retrotransposons in sweet potato, Table S2: Digital fingerprints of the 105 sweet potato accessions generated by the 6 RBIP primer pairs, Table S3: Phenotypic traits of the 30 sweet potato varieties.

\section{References}

1. Monden, Y. et al. Construction of a linkage map based on retrotransposon insertion polymorphisms in sweet potato via high-throughput sequencing. Breed Sci. 65, 145-153 (2015).

2. Su, W. J. et al. Genome-wide assessment of population structure and genetic diversity and development of a core germplasm set for sweet potato based on specific length amplified fragment 
(SLAF) sequencing. PloS One. 12, https://doi.org/10.1371/journal.pone.0172066 (2017).

3. Wang, H. Y., Zhai, H., Wang, Y. P., He, S. Z. \& Liu, Q. C. RAPD fingerprint and genetic variation of 30 main sweet potato varieties from China. Mol Plant Breed. 7, 879-884 (2009).

4. Hu, L. et al. Genetic diversity analysis of landraces and improved cultivars in sweet potato. Jiangsu J Agric Sci. 26, 925-935 (2010).

5. Moulin, M. M., Rodrigues, R. \& Cláudia, M. G. A comparison of RAPD and ISSR markers reveals genetic diversity among sweet potato landraces (Ipomoea batatas (L.) Lam.). Acta Sci Agron. 34, 139-147(2012).

6. Li, Q. et al. Genetic Diversity and Genetic Tendency of Main Chinese Sweet potato Cultivars. Jiangsu Journal of Agricultural Sciences. 25, 253-259 (2009).

7. Liu, D. et al. AFLP fingerprinting and genetic diversity of main sweet potato varieties in China. $J$ Integr Agric. 11, 1424-1433 (2012).

8. Wang, Z. Y. et al. Characterization and development of EST-derived SSR markers in cultivated sweet potato (Ipomoea batatas). BMC Plant biol. 11, https://doi.org/10.1186/1471-2229-11-139 (2011).

9. Yang, X. S. et al. Molecular diversity and genetic structure of 380 sweet potato accessions as revealed by SSR markers. J Integr Agric. 14, 633-641 (2015).

10. Meng, Y. S. et al. Q. C. SSR fingerprinting of 203 sweet potato (Ipomoea batatas (L.) Lam.) varieties. J Integr Agric. 17, 86-93 (2018).

11. Jiang, S., Zong, Y., Yue, X. Y., Postman, J. \& Teng, Y. W. Prediction of retrotransposons and assessment of genetic variability based on developed retrotransposon-based insertion polymorphism (RBIP) markers in Pyrus L. Mol Genet Genomics. 290, 225-237 (2015).

12. Peterson, D. G. et al. Integration of Cot analysis, DNA cloning, and high-throughput sequencing facilitates genome characterization and gene discovery. Genome Res. 12, 795-807 (2002).

13. Havecker, E. R., Xiang, G. \& Voytas, D. F. The diversity of LTR retrotransposons. Genome Biol. 5, https://doi.org/10.1186/gb-2004-5-6-225 (2004).

14. Bergman, C. M. \& Quesneville, H. Discovering and detecting transposable elements in genome sequences. Brief Bioinform. 8, 382-392 (2007).

15. Wu, J. et al. The genome of the pear (Pyrus bretschneideri Rehd.). Genome Res. 23, 396-408 (2013).

16. Galindo-González, L., Mhiri, C., Deyholos, M. K. \& Grandbastien, M. A. LTR-retrotransposons in plants: engines of evolution. Gene. 626, 14-25 (2017).

17. Liang, Y., Lenz, R. R. \& Dai, W. Development of retrotransposon-based molecular markers and their application in genetic mapping in chokecherry (Prunus virginiana L.). Mol breed. 36, https://doi.org/10.1007/s11032-016-0535-2 (2016).

18. Nashima, K. et al. Retrotransposon-based insertion polymorphism markers in mango. Tree Genet Genomes. 13, https://doi.org/10.1007/s11295-017-1192-2 (2017).

19. Alexandra, Y. et al. Analysis of genetic diversity and evolutionary relationships among hexaploid wheats Triticum L. using LTR-retrotransposon-based molecular markers. Genet Resour Crop Evol. 65, 
187-198 (2018).

20. Zong, Y. et al. Phylogenetic relationship and genetic background of blueberry (Vaccinium spp.) based on retrotransposon based SSAP molecular markers. Sci Hortic. 247, 116-122 (2019).

21. Strioto, D. K. et al. D. F. P. S. Development and use of retrotransposons-based markers (IRAP/REMAP) to assess genetic divergence among table grape cultivars. Plant Genet Resour. 17, 272-279 (2019).

22. Ghonaim, M. et al. High-throughput retrotransposon-based genetic diversity of maize germplasm assessment and analysis. Mol Bio Rep. 47, 1589-1603 (2020).

23. Ouafae, P. et al. Using two retrotransposon-based marker systems (SRAP and REMAP) for genetic diversity analysis of Moroccan Argan tree. Mol Bio Res communications. 9, 93-103 (2020).

24. Zhou, J. Y. et al. Retrotransposon-based genetic variation and population structure of Impatiens macrovexilla Y. L. Chen in natural habitats and the implications for breeding. Sci. Hort. 276, https://doi.org/10.1016/j.scienta.2020.109753 (2021).

25. Yang, J. et al. The haplotype-resolved genome sequence of hexaploid Ipomoea batatas reveals its evolutionary history. Research Gate. doi: http://dx.doi.org/10.1101/064428 (2016).

26. Yeh, F. C., Yang, R. C. \& Boyle, T. POPGENE version 1.32: Microsoft Windows-based freeware for population genetic analysis, quick user guide (Center for International Forestry Research, University of Alberta, Edmonton, Alberta, Canada, 1999).

27. Earl, D. A. \& Vonholdt, B. M. STRUCTURE HARVESTER: a website and program for visualizing STRUCTURE output and implementing the Evanno method. Conserv Genet Resour. 4, 359-361 (2012).

28. Evanno, G., Regnaut, S. \& Goudet, J. Detecting the number of clusters of individuals using the software STRUCTURE: a simulation study. Mol Ecol. 14, 2611-2620 (2005).

29. Si, Z. Z. et al. A genome-wide BAC-end sequence survey provides first insights into sweet potato (Ipomoea batatas (L.) Lam.) genome composition. BMC Genomics. 17, https://doi.org/10.1186/s12864-016-3302-1 (2016).

30. Schnable, P. S. et al. The B73 maize genome: complexity, diversity, and dynamics. Science. 326, 1112-1115 (2009).

31. Cavallini, A., Natali, L., Zuccolo, A., Giordani, T. \& Morgante, M. Analysis of transposons and repeat composition of the sunflower (Helianthus annuus L.) genome. Theor Appl Genet. 120, 491-508 (2010).

32. Cossu, R. M., Buti, M., Giordani, T., Natali, L. \& Cavallini, A. A computational study of the dynamics of LTR retrotransposons in the Populus trichocarpa genome. Tree Genet Genomes. 8, 61-75 (2012).

33. Diwan, N. \& Cregan, P. B. Automated sizing of fluorescent-labeled simple sequence repeat (SSR) markers to assay genetic variation in soybean. Theor Appl Genet. 95, 723-733 (1997).

34. Wierdl, M., Dominska, M. \& Petes, T. D. Microsatellite instability in yeast: dependence on the length of the microsatellite. Genetics. 146, 769-779 (1997). 
35. Yamada, N. A., Smith, G. A., Castro, A., Roques, C. N. \& Farber, R. A. Relative rates of insertion and deletion mutations in dinucleotide repeats of various lengths in mismatch repair proficient mouse and mismatch repair deficient human cells. Mutat Res. 499, 213-225 (2002).

36. Kalendar, R. et al. Analysis of plant diversity with retrotransposon-based molecular markers. Heredity. 106, https://doi.org/10.1038/hdy.2010.93 (2011).

37. Lu, S. Y., Liu, Q. C. \& Li, W. J. Sweet potato Breedingpp. 7-17(China Agriculture Press, Beijing, China, 1998). (in Chinese)

38. Li, Q. et al. Genetic diversity in main parents of sweet potato in China as revealed by ISSR marker. Acta Agronomica Sinica. 34, 972-977 (2008). (in Chinese)

39. Saghai-Maroof, M. A., Soliman, K. M., Jorgensen, R. A. \& Allard, R. W. Ribosomal DNA spacer-length polymorphisms in barley: Mendelian inheritance, chromosomal location, and population dynamics. Proc Natl Acad Sci. 81, 8014-8018 (1984).

40. Rozen, S. Primer3: a software component for picking PCR primer(1996).

41. Currie-Fraser, E., Shah, P. \& True, S. Data analysis using GeneMapper ${ }^{\circledR}$ v4.1: Comparing the Newest Generation of GeneMapper Software to Legacy Genescan ${ }^{\circledR}$ and Genotyper® Software.J Biomol Tech.21 (2010).

42. Botstein, D. R., White, R. L., Skolnick, M. H. \& Davis, R. W. Construction of a genetic linkage map in man using restriction fragment length polymorphisms. Am J Hum Genet. 32, 314-331 (1980).

43. Pritchard, J. K., Stephens, M. J. \& Donnelly, P. J. Inference of population structure using multilocus genotype data. Genetics. 155, 945-959 (2000).

44. Falush, D., Stephens, M. \& Pritchard, J. K. Inference of population structure using multilocus genotype data: dominant markers and null alleles. Mol Ecol Notes. 7, 574-578 (2007).

45. Rosenberg, N. A. DISTRUCT: a program for the graphical display of population structure. Mol Ecol Notes. 4, 137-138 (2004).

46. Nei, M. \& Li, W. H. Mathematical model for studying genetic variation in terms of restriction endonucleases. Proc Natl Acad Sci. 76, 5269-5273 (1979).

47. Rohlf, F. J. NTSYS-pc: numerical taxonomy and multivariate analysis system(1992).

48. Kumar, S., Stecher, G., Li, M., Knyaz, C. \& Tamura, K. MEGA X: molecular evolutionary genetics analysis across computing platforms. Mol Biol Evol. 35, 1547-1549 (2018).

49. Team, R. C. R. A Language and Environment for Statistical Computing. Computing Team, RDCVienna, Austria. doi: 10.1007/s10985-007-9065-x[18000755](2013).

50. Excoffier, L. \& Lischer, H. E. L. Arlequin suite ver 3.5: a new series of programs to perform population genetics analyses under Linux and Windows. Mol Ecol Resour. 10, 564-567 (2010).

51. Weir, B. S. \& Cockerham, C. C. Estimating f-statistics for the analysis of population structure. Evolution. 38, 1358-1370 (1984).

\section{Figures}



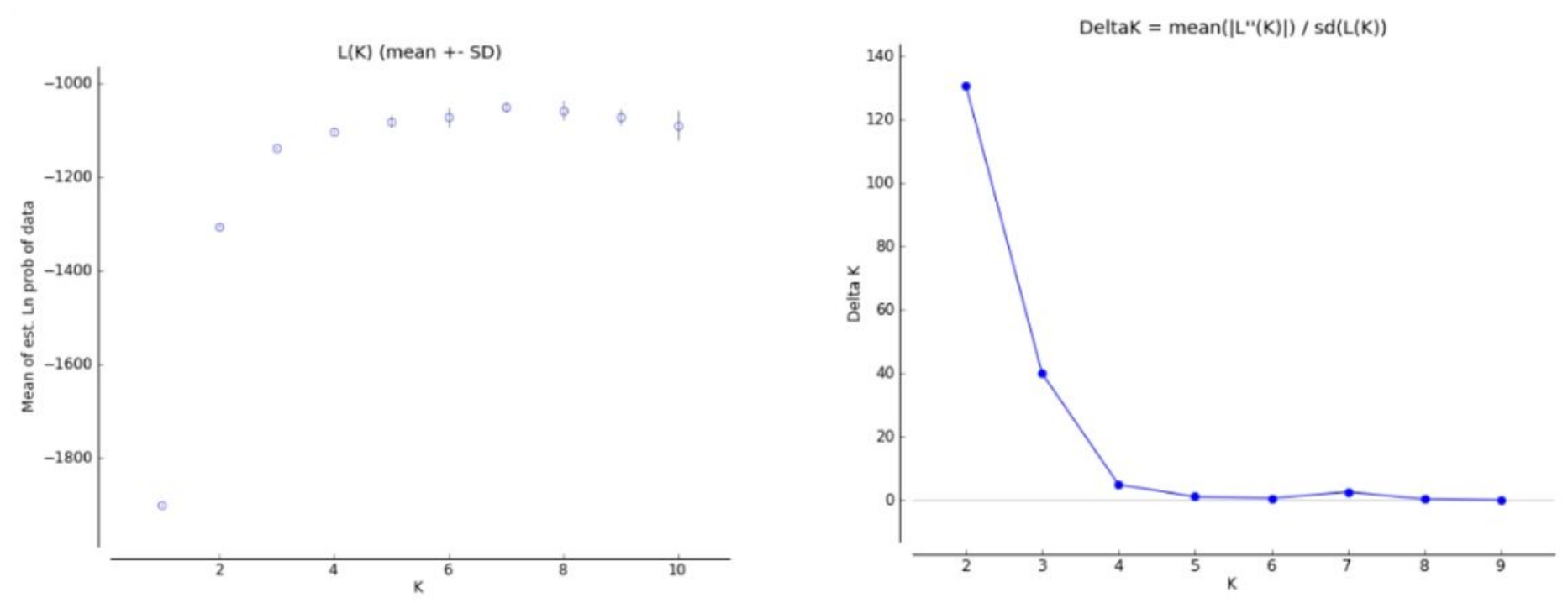

\section{Figure 1}

Modeling of cluster number for sweet potato using STRUCTURE. L(K) (left) and Delta K (right) were calculated in accordance with the method of Evanno et al.
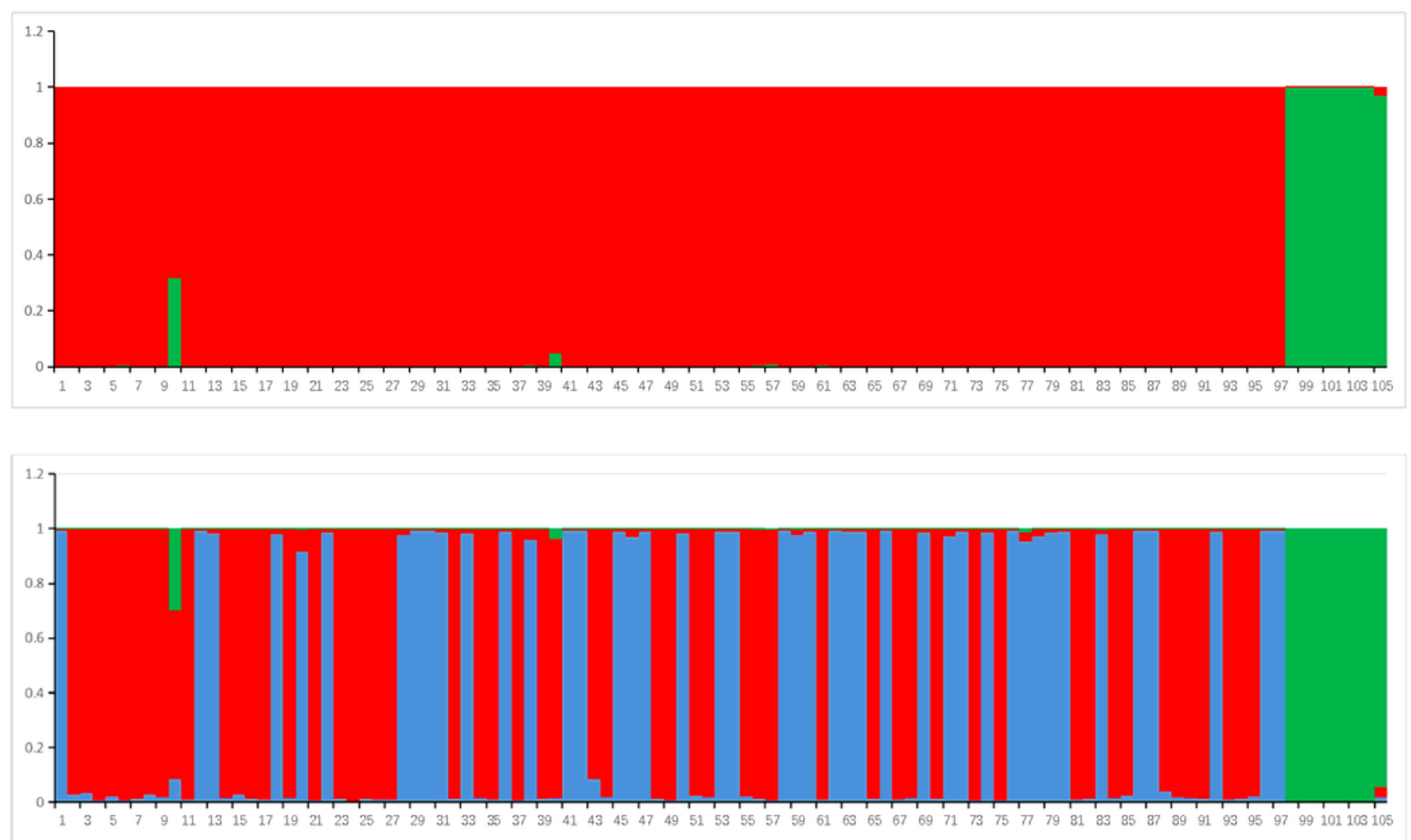

\section{Figure 2}

Genetic relationships among the 105 accessions of sweet potato revealed by a Bayesian modeling approach under $\mathrm{K}=2$ (top) and $\mathrm{K}=3$ (bottom) (numbers 1 to 105 represent the 105 sweet potato varieties) 


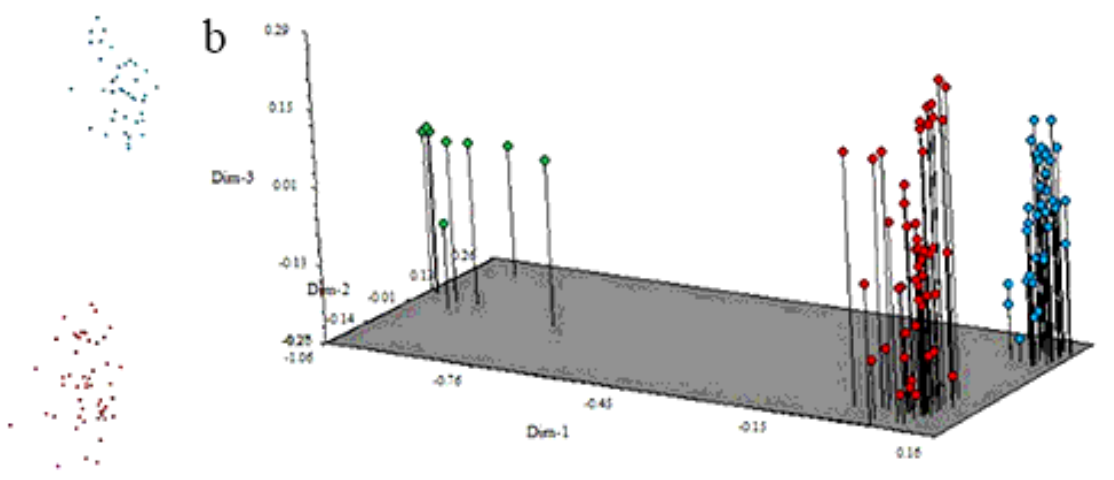

Figure 3

Two-dimensional and three-dimensional PCAs among the 105 sweet potato accessions based on 6 RBIP primer pairs (I repre-sented by green, II by red, and III by blue) 


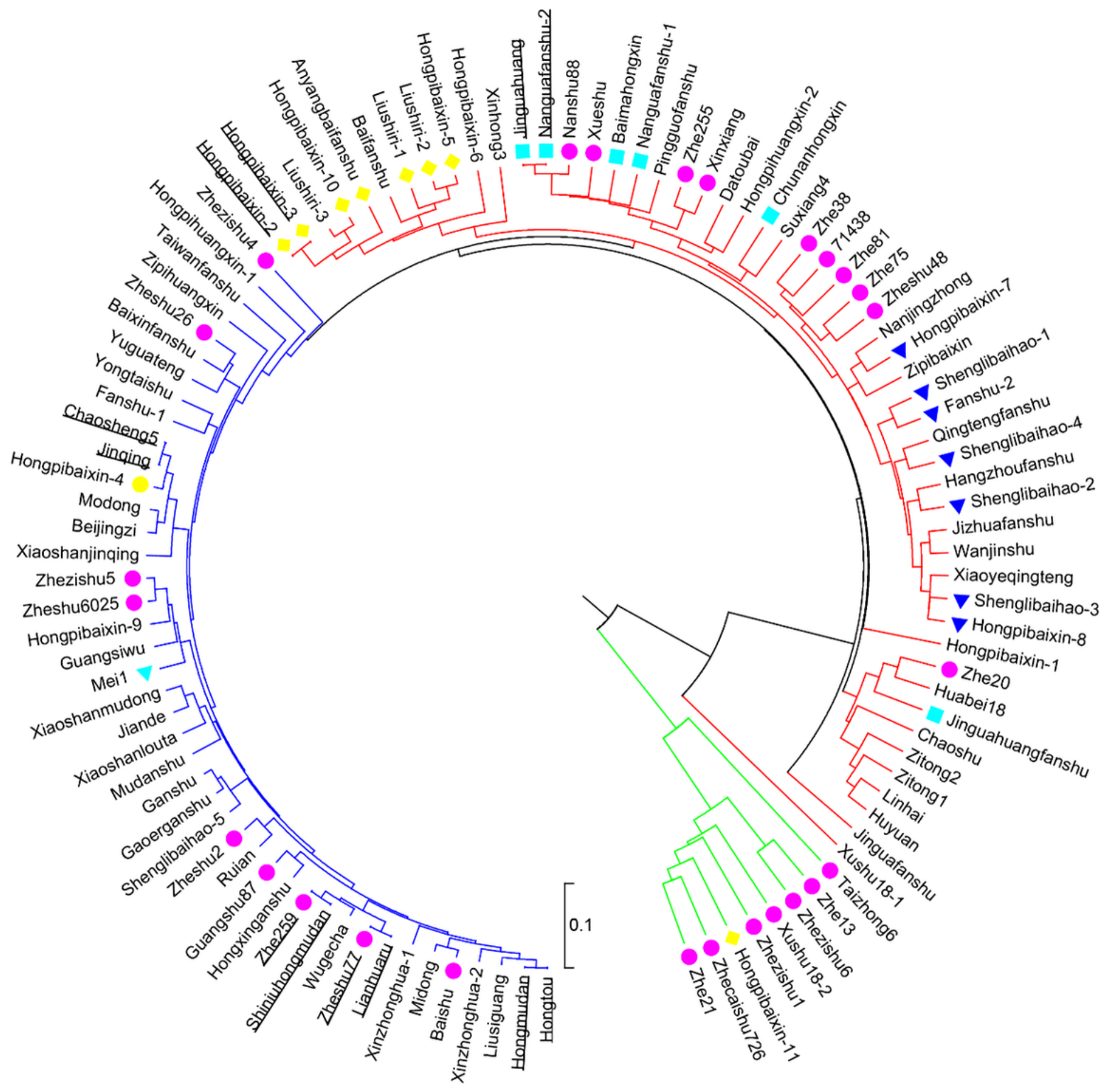

\section{Figure 4}

Dendrogram of 105 sweet potato accessions based on their genetic distances. UPGMA cluster analysis based on Dice's similarity coefficients (Nei and Li, 1979) was used to generate the dendrogram. 'Green branches', 'red branches' and 'blue branches' repre-sent the subbranches. Purple circles indicate improved varieties. Green triangles represent foreign varieties. 


\section{Percentages of Molecular Variance}

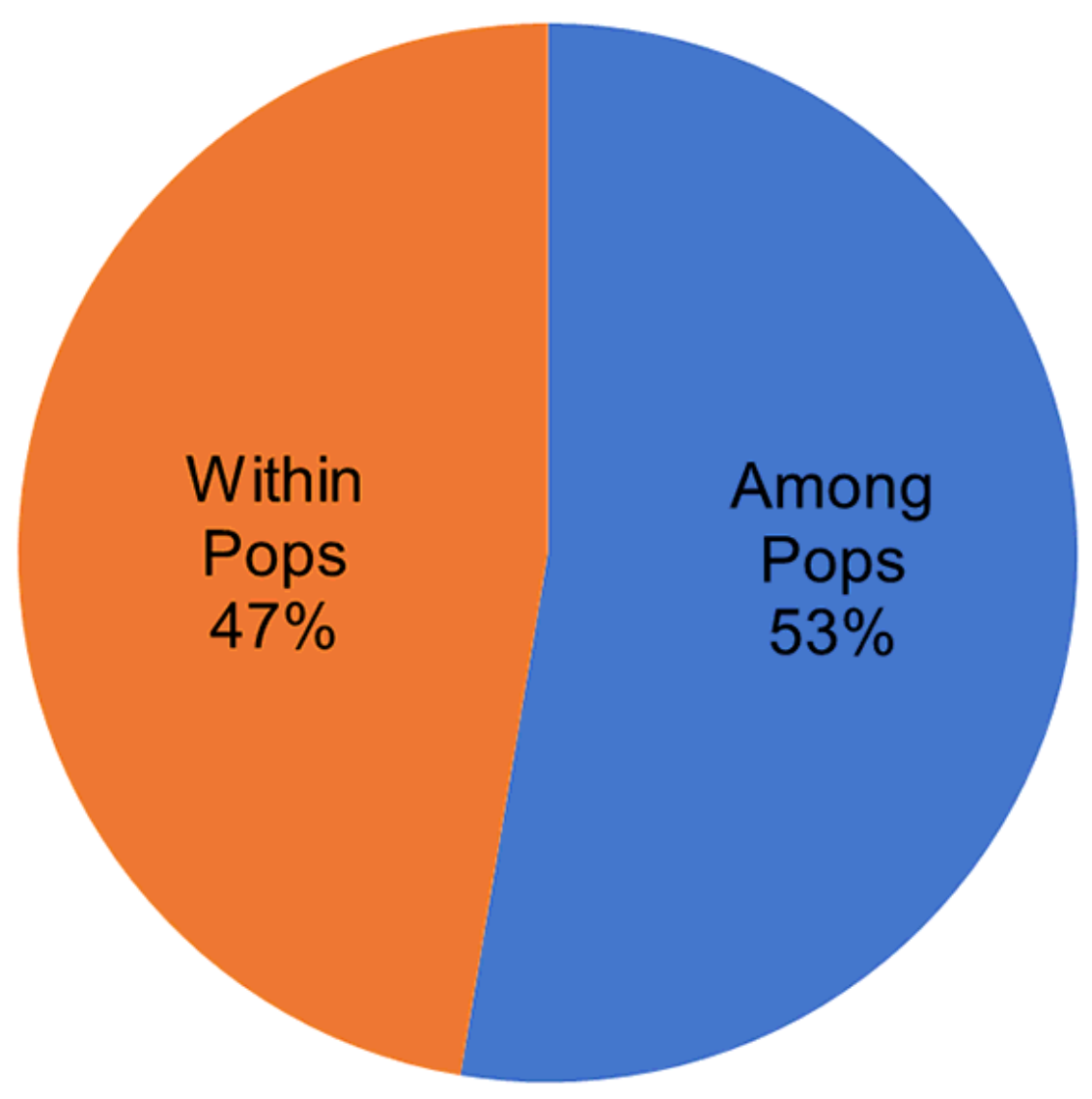

Figure 5

The percentages of molecular variance within and among three populations

\section{Supplementary Files}

This is a list of supplementary files associated with this preprint. Click to download.

- SupplementaryFigure1.docx

- SupplementaryTable1.xlsx

- SupplementaryTable2.xlsx

- SupplementaryTable3.xlsx 